\title{
High-resolution solid-state NMR study of isotactic polypropylenes
}

\author{
O. Fričová ${ }^{*}$, M. Uhrínová ${ }^{1}$, V. Hronský ${ }^{1}$, M. Koval'aková ${ }^{1}$, D. Olčák $k^{1}$, I. Chodák ${ }^{2}, J$. Spěváček ${ }^{3}$ \\ ${ }^{1}$ Department of Physics, Faculty of Electrical Engineering and Informatics, Technical University of Košice, Park \\ Komenského 2, 04200 Košice, Slovakia \\ ${ }^{2}$ Polymer Institute, Slovak Academy of Sciences, Dúbravská cesta 9, 84236 Bratislava, Slovakia \\ ${ }^{3}$ Institute of Macromolecular Chemistry, Academy of Sciences of the Czech Republic, Heyrovsky Sq. 2, 16206 Prague 6, \\ Czech Republic
}

Received 11 July 2011; accepted in revised form 25 September 2011

\begin{abstract}
The high-resolution solid-state ${ }^{13} \mathrm{C}$ NMR spectra were recorded for metallocene (m) and Ziegler-Natta (ZN) isotactic polypropylenes (iPP) in pelletized form using cross polarization (CP) and magic angle spinning (MAS) techniques within the temperature range of $20-160^{\circ} \mathrm{C}$. Besides the $\mathrm{CP}$ MAS experiments also the MAS ${ }^{13} \mathrm{C}$ NMR spectra (without $\mathrm{CP}$ ), MAS ${ }^{1} \mathrm{H}$ NMR spectra and rotating frame spin-lattice relaxation times $T_{1 \rho}\left({ }^{13} \mathrm{C}\right)$ were measured at elevated temperatures. With the rise of temperature the splitting of $\mathrm{CH}_{2}, \mathrm{CH}$ and $\mathrm{CH}_{3}$ signals into two components was detected in ${ }^{13} \mathrm{C}$ NMR spectra and assigned to amorphous and crystalline phases. The temperature dependences of chemical shifts and integral intensities obtained from the deconvoluted spectra provided information on the main chain and $\mathrm{CH}_{3}$ groups motions in amorphous and crystalline regions of studied samples. While $T_{1 \rho}\left({ }^{13} \mathrm{C}\right)$ values show that the rate of segmental motion in amorphous regions in $\mathrm{m}$-iPP and $\mathrm{ZN}$-iPP is virtually the same, larger linewidths in ${ }^{13} \mathrm{C}$ and ${ }^{1} \mathrm{H} \mathrm{NMR}$ spectra indicate somewhat larger restraints of the motion in amorphous regions of $\mathrm{ZN}-\mathrm{iPP}$.
\end{abstract}

Keywords: material testing, metallocene isotactic polypropylene, Ziegler-Natta isotactic polypropylene, solid state NMR, segmental motion

\section{Introduction}

Since the commercialization of Ziegler-Natta process of polypropylene synthesis, this technology was for decades almost the only source of all grades of polypropylene (PP). Only at the end of the last century a new process was developed, based on metallocene catalysis. This process provides new types of metallocene PP (m-PP) different from previous Ziegler Natta PP types (ZN-PP), the main difference consisting in the production of grades with different stereoregularity (isotactic, syndiotactic, hemi-isotactic, atactic) [1] or narrow polydispersity of the polymer chains, compared to Ziegler-Natta catalysts, which produces only highly polydisperse isotactic polymers. The tacticity of isotactic (i) $\mathrm{m}-$ PP and ZN-PP is virtually the same (98\% of isotactic diads), though the configurational defects are more frequent in m-iPP [2]; this might be reflected in a lower melting temperature of $\mathrm{m}-\mathrm{iPP}$ in comparison with $\mathrm{ZN}$-iPP.

Comparing to $\mathrm{ZN}$-iPP, m-iPP offers a unique balance of stiffness, transparency, and organoleptic properties which is not achievable with $\mathrm{ZN}$-iPP. On the other hand, $\mathrm{m}$-iPP is usually less rigid than $\mathrm{ZN}$ iPP homopolymers. Thus, any additional information on similarity or differences in m-iPP vs. ZNiPP behaviour seems to be of scientific as well as

\footnotetext{
${ }^{*}$ Corresponding author, e-mail: olga.fricova@tuke.sk
}

(c) BME-PT 
commercial importance. NMR investigation is considered to be one of the basic relevant methods.

The high-resolution solid-state ${ }^{13} \mathrm{C}$ NMR studies of iPP reported NMR spectra recorded with combination of magic angle spinning (MAS), cross polarisation (CP) and dipolar decoupling (DD) techniques [3-14]. Since iPP can crystallize in several crystalline forms, depending on the crystallization temperature and on the presence of specific nucleating agents, the shape of the spectra was found to depend strongly on the physical treatment of the sample and the temperature at which the NMR experiment was carried out.

Three symmetrical resonance lines related to the $\mathrm{CH}_{2}$, $\mathrm{CH}$ and $\mathrm{CH}_{3}$ groups were observed in the ${ }^{13} \mathrm{C}$ NMR spectra measured on iPP sample crystallizing in the hexagonal $\beta$-form at room temperature. On the other hand, the sample crystallizing in monoclinic structure ( $\alpha$-form) prepared by an annealing procedure gives the spectra with the $\mathrm{CH}_{2}$ and $\mathrm{CH}_{3}$ lines split into the doublets. This splitting which appeared in NMR experiments carried out with $\mathrm{CP}$ as well as without the application of the CP technique, was shown to be associated with two different packing sites in crystals $[4,7,11]$. With increasing temperature the lines of the $\mathrm{CH}_{2}$ and $\mathrm{CH}_{3}$ doublets with lower chemical shifts were shown to be gradually shifted to the positions with higher chemical shifts and merged into singlet lines. A more vigorous molecular motion activated by the rise of temperature, averaged each crystalline carbon resonance over the two sites, and resulted in the disappearance of the doublets [11]. An absence of the abovementioned crystalline doublets in iPP crystallizing in the hexagonal ( $\beta$-form) was explained by the absence of different packing sites of chains in crystals [4].

It was shown that the increase of the temperature gives rise to new resonance lines of the $\mathrm{CH}_{2}$ and $\mathrm{CH}$ groups with chemical shifts between the lines observed at room temperature and those observed in the iPP solution. These lines detected as separated lines in the MAS DD spectra and as shoulders of the original lines in the CP MAS DD experiment, were assigned to the carbons in amorphous regions of the partially crystalline iPP [7].

To reveal if there are some differences in the structure and molecular motion between $\mathrm{m}-\mathrm{iPP}$ and $\mathrm{ZN}$ iPP we report the high-resolution ${ }^{13} \mathrm{C}$ NMR study of the $\mathrm{m}$-iPP and $\mathrm{ZN}$-iPP crystallizing predominantly in the hexagonal $\beta$-form, based on CP MAS DD and single pulse MAS DD techniques at temperatures ranging from room temperature up to the melting point of the polymer. According to our knowledge, m-iPP was not studied by solid-state NMR until now.

\section{Experimental}

\subsection{Materials}

Two samples of predominantly isotactic PP prepared in pelletized form were used for the study METOCENE HM $562 \mathrm{~N}$ (m-iPP, Lyondellbasell) prepared by metallocene-catalysed polymerization and TATREN HG 1007 (ZN-iPP, Slovnaft, Slovakia) prepared by Ziegler-Natta polymerization. The degree of crystallinity $X_{\mathrm{c}}$, taking the value of $209 \mathrm{~J} / \mathrm{g}$ [15] as the heat of fusion of $100 \%$ crystalline iPP, and melting temperature $T_{\mathrm{m}}$ of the samples were determined by DSC (Mettler Toledo DSC 821 (Greifensee, Switzerland), second run, heating rate $10^{\circ} \mathrm{C} /$ minute), the glass transition temperature $T_{\mathrm{g}}$ was determined by DMTA experiment (TA Analysis Q800 (New Castle, DE, USA), heating rate $2{ }^{\circ} \mathrm{C} /$ minutes, frequency $10 \mathrm{~Hz}$ ). The values are listed in Table 1. The samples were not treated prior to NMR experiments except the cutting of pellets into smaller pieces in order to achieve stable spinning of the NMR rotor.

Table 1. The degree of crystallinity $X_{\mathrm{c}}$, melting temperature $T_{\mathrm{m}}$ and glass transition temperature $T_{\mathrm{g}}$ of $\mathrm{m}$-iPP and ZN-iPP samples

\begin{tabular}{|l|c|c|c|}
\hline \multicolumn{1}{|c|}{ Sample } & $\boldsymbol{X}_{\mathbf{c}}[\mathbf{\%}]$ & $\boldsymbol{T}_{\mathbf{m}}\left[{ }^{\circ} \mathbf{C}\right]$ & $\boldsymbol{T}_{\mathbf{g}}\left[{ }^{\circ} \mathbf{C}\right]$ \\
\hline $\mathrm{m}-\mathrm{iPP}$ & 52 & 145.2 & 12 \\
\hline $\mathrm{ZN}-\mathrm{iPP}$ & 55 & 163.6 & 10 \\
\hline
\end{tabular}

\subsection{NMR measurements}

The high-resolution solid-state ${ }^{13} \mathrm{C}$ NMR measurements were carried out on a $400 \mathrm{MHz}$ Varian solidstate NMR spectrometer (Palo Alto, CA, USA). The high-resolution ${ }^{13} \mathrm{C}$ NMR spectra were recorded at the resonance frequency of approximately $100 \mathrm{MHz}$ with the use of $4 \mathrm{~mm}$ rotors and magic angle spinning frequency of $6 \mathrm{kHz}$. In $\mathrm{CP}$ experiments the Hartmann-Hahn condition was obtained with the radio frequency field strength of $51 \mathrm{kHz}$, a contact time $1 \mathrm{~ms}$ and relaxation delay between two consecutive scans $5 \mathrm{~s}$. The high power proton-decoupling field of $85 \mathrm{kHz}$ was applied during data acquisition. 
The CP MAS ${ }^{13} \mathrm{C}$ NMR experiments were carried out within the temperature range of $20-160^{\circ} \mathrm{C}$ and the MAS ${ }^{13} \mathrm{C}$ NMR (without $\mathrm{CP}$ ) spectra were recorded at the temperatures 20,90 and $160^{\circ} \mathrm{C}$ with relaxation delay $240 \mathrm{~s}$. It has to be stressed that the measurement at $160^{\circ} \mathrm{C}$ was performed on the molten sample of m-iPP. Besides the high-resolution solid-state ${ }^{13} \mathrm{C}$ NMR spectra also a rotating frame spin-lattice relaxation times $T_{1 \rho}\left({ }^{13} \mathrm{C}\right)$ were measured at 64 and $90^{\circ} \mathrm{C}$. A spin locking experiment was performed under CP and MAS conditions. During spin-lock pulse, which was up to $50 \mathrm{~ms}$, and detection period the dipolar decoupling fields of 85 and $100 \mathrm{kHz}$ were applied, respectively. The ${ }^{13} \mathrm{C}$ spins were locked with the field of $77 \mathrm{kHz}$.

The chemical shifts and integral intensities were acquired from the deconvoluted spectra. All deconvolutions were done assuming the Lorentzian's lineshapes. The chemical shifts were referenced to the TMS using adamantane as an external standard and they were determined with accuracy better than $0.02 \mathrm{ppm}$. The calibration of the temperature inside the rotor was performed with the use of the measured temperature dependence of the ${ }^{207} \mathrm{~Pb} \mathrm{NMR}$ chemical shift of lead nitrate [16]. The temperature was controlled by the variable temperature system unit with the accuracy of $\pm 0.1^{\circ} \mathrm{C}$, however, the gradient of the temperature along the axis of the rotor is significantly larger and depends on the temperature.

${ }^{1} \mathrm{H}$ MAS NMR spectra were measured on the same instrument at the frequency $400 \mathrm{MHz}$. The duration of the $90^{\circ}$ radio-frequncy pulse was $2.7 \mu \mathrm{s}$, spinning frequency was $6 \mathrm{kHz}$.

\section{Results and discussion}

The CP MAS ${ }^{13} \mathrm{C}$ NMR spectra measured at different temperatures on the solid $\mathrm{m}$-iPP sample and the MAS ${ }^{13} \mathrm{C}$ NMR spectrum measured at $160^{\circ} \mathrm{C}$ without CP (due to the fact that the sample was molten at this temperature and high molecular mobility made the CP inefficient at this temperature) are depicted in Figure 1. In the spectrum measured at room temperature three broad symmetrical resonance lines can be observed with the chemical shifts of $44.45,26.63$ and 22.20 ppm related to $\mathrm{CH}_{2}, \mathrm{CH}$ and $\mathrm{CH}_{3}$ carbons, respectively. They reflect broad distributions of possible conformations of iPP chains at room temperature which is slightly

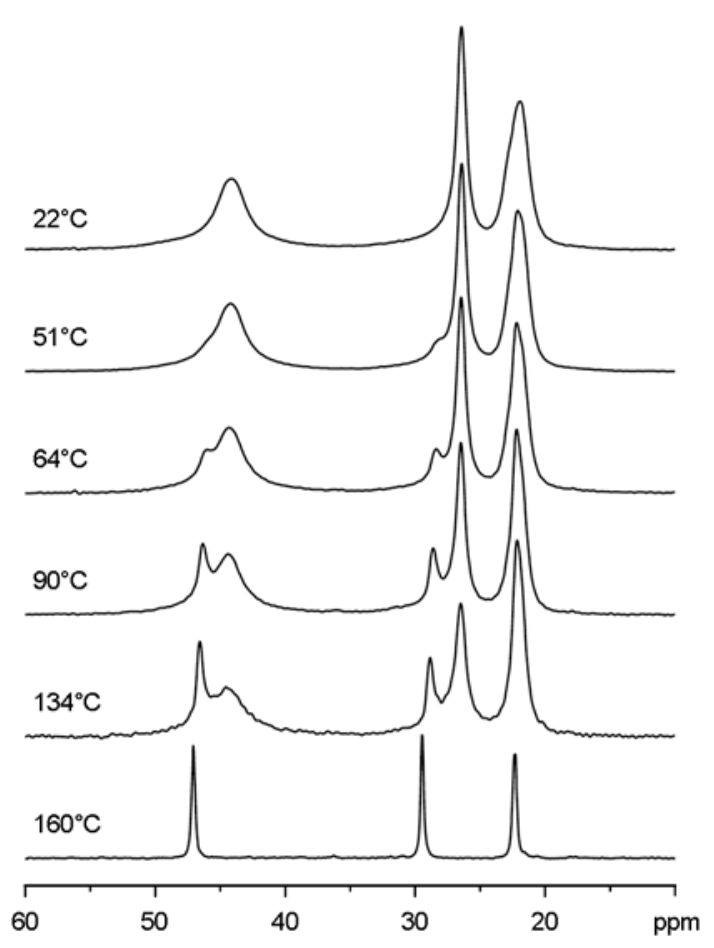

Figure 1. CP MAS ${ }^{13} \mathrm{C}$ NMR spectra of m-iPP measured at temperatures as indicated, except the spectrum measured at $160^{\circ} \mathrm{C}$ for the molten sample using single pulse MAS ${ }^{13} \mathrm{C}$ NMR technique. CP MAS ${ }^{13} \mathrm{C}$ NMR spectra were normalized

above the glass transition. A small asymmetry of the $\mathrm{CH}_{3}$ line will be discussed later. Three resonance lines are also observed in the spectrum recorded at $160^{\circ} \mathrm{C}$, however, they are considerably narrower and with higher chemical shifts of 47.09, 29.48 and $22.36 \mathrm{ppm}$ when compared with those observed in the spectrum measured at room temperature. The conspicuous line narrowing observed in this spectrum reflects the rapid changes of conformations in the molten sample.

Figure 1 shows that besides the lines observed at room temperature, the new resonance lines of $\mathrm{CH}_{2}$ and $\mathrm{CH}$ carbons appear in the measured spectra with the rise of temperature. Similar effect was in the past observed in the spectra obtained using MAS DD ${ }^{13} \mathrm{C}$ NMR technique, i. e., without $\mathrm{CP}$, on the PP crystallizing in $\alpha$-form and these lines were assigned to the carbons within the chains of amorphous regions $[7,11]$. Therefore, additional lines detected for $\mathrm{m}$-iPP at temperatures above $51^{\circ} \mathrm{C}$ can be associated with the $\mathrm{CH}_{2}$ and $\mathrm{CH}$ carbons in amorphous regions of m-iPP.

The main characteristics of the spectra measured for $\mathrm{ZN}$-iPP exhibit a similar behaviour as those 
shown for m-iPP confirming that both iPP samples are in the hexagonal $\beta$-form $[4,6,7]$. However, small differences between the spectra measured at the same temperature can be found. In spectra measured at elevated temperatures the resonance lines related to the $\mathrm{CH}_{2}$ and $\mathrm{CH}$ carbons in amorphous regions of $\mathrm{m}$-iPP are better resolved than those of $\mathrm{ZN}$-iPP. The $\mathrm{CH}_{2}$ lines of the spectra measured on both samples at $64^{\circ} \mathrm{C}$ depicted in Figure 2 illustrate mentioned differences. Therefore, it can be deduced that the onset of the molecular processes in the amorphous regions, which are associated with appearance of new lines, is observed in $\mathrm{m}$-iPP at lower temperature as compared with that in $\mathrm{ZN}$-iPP. The resonance lines discussed above apply to the main chain carbons of both polymers and therefore the changes observed in the spectra have to be associated with segmental motion in iPP samples. The differences discussed above can then indicate somewhat higher chain mobility in the amorphous regions of m-iPP. Alternative explanation that the observed differences might be in connection with the dispersion of chemical shifts seems to be for two highlyisotactic polymers rather improbable. The segmental motion in amorphous regions of iPP is related to the glass transition relaxation ( $\beta$-relaxation) that was recently studied by wide-line ${ }^{1} \mathrm{H}$ NMR [17]. To confirm a difference discussed above we also measured ${ }^{1} \mathrm{H}$ NMR spectra under MAS with the spinning rate of $6 \mathrm{kHz}$ at $71^{\circ} \mathrm{C}$. The splitting of the amorphous signal into components related to the protons of different PP groups can be seen in Figure 2. Evidently, due to the larger restrictions in chain mobility of $\mathrm{ZN}-\mathrm{iPP}$ in comparison with $\mathrm{m}$-iPP the better resolu-

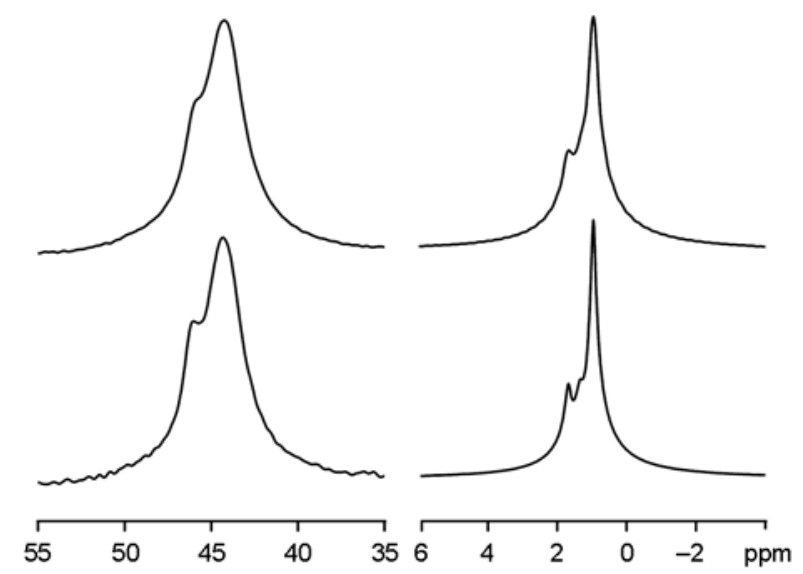

Figure 2. The $\mathrm{CH}_{2}$ lines of the normalized CP MAS ${ }^{13} \mathrm{C}$ NMR spectra (left) and ${ }^{1} \mathrm{H}$ MAS NMR spectra (right) measured at 64 and $71^{\circ} \mathrm{C}$, respectively, for m-iPP (bottom) and $\mathrm{ZN}-\mathrm{iPP}$ (top) tion of the spectrum is observed in the case of $\mathrm{m}$ iPP.

In spite of the fact that no splitting of the $\mathrm{CH}_{3}$ lines was observed in the spectra, the change of this line shape, which is very similar for both samples, is of interest. At $22^{\circ} \mathrm{C}$ at the left hand side of this peak and at higher temperature at the right hand side of this peak a shoulder is formed, at $134^{\circ} \mathrm{C}$ the line seems to be symmetrical. The $\mathrm{CH}_{3}$ line therefore consists of two overlapping lines shown in Figure 3 whose intensities strongly depend on temperature.

The line indicated as the left hand side shoulder at $22^{\circ} \mathrm{C}$ can be related to the most mobile $\mathrm{CH}_{3}$ groups in the amorphous regions and that indicated as the right hand side shoulder at higher temperatures to less mobile $\mathrm{CH}_{3}$ groups in crystalline and probably also amorphous regions. With increasing temperature, a mobility of the less mobile $\mathrm{CH}_{3}$ groups increases and therefore also the intensity of the right hand side shoulder decreases. At sufficiently high temperatures only a small fraction of $\mathrm{CH}_{3}$
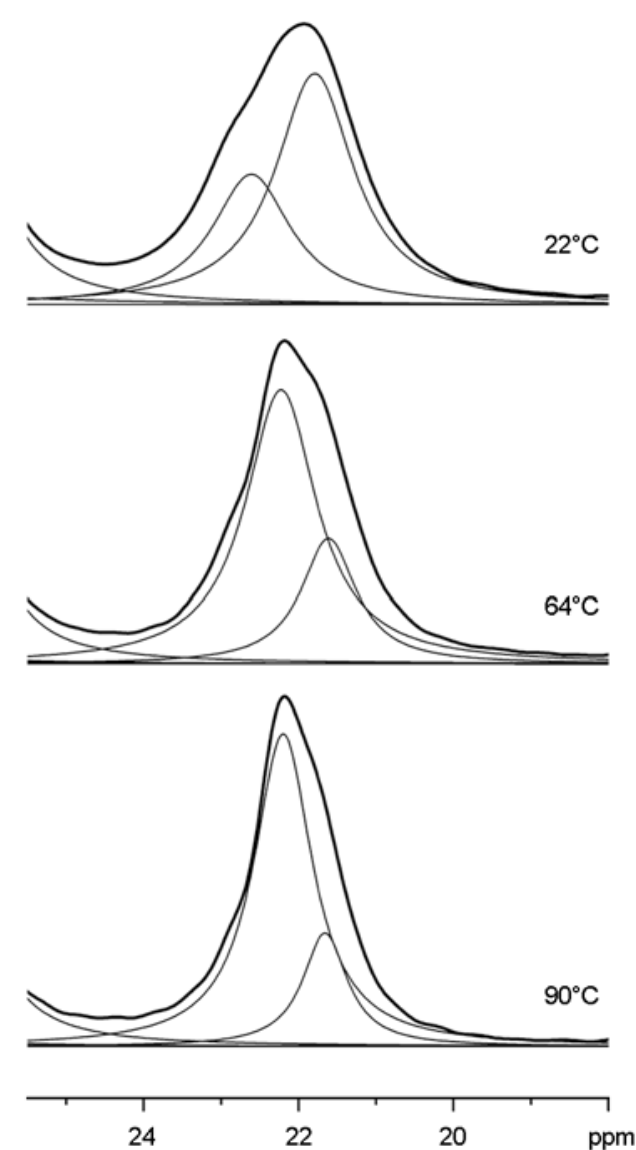

Figure 3. Deconvolutions of $\mathrm{CH}_{3}$ lines of the CP MAS ${ }^{13} \mathrm{C}$ NMR spectra measured on $\mathrm{m}$-iPP at different temperatures 


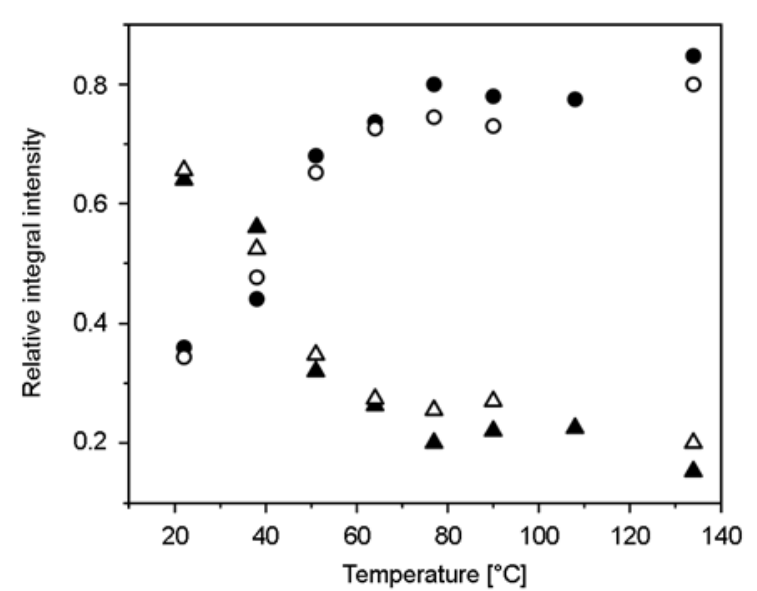

Figure 4. The temperature dependences of the relative integral intensity of the $\mathrm{CH}_{3}$ resonance lines related to the more mobile (circles) and less mobile $\mathrm{CH}_{3}$ groups (triangles) of m-iPP (solid symbols) and $\mathrm{ZN}$-iPP (open symbols)

groups has still a low mobility. The temperature dependences of the relative integral intensities of both $\mathrm{CH}_{3}$ lines obtained by deconvolution, which are shown in Figure 4, support assumption described above. Generally, intensities can be influenced by the transfer of magnetisation during the cross polarisation. However, only a slight difference in motion of $\mathrm{CH}_{3}$ groups in amorphous and crystalline regions can be deduced from $\mathrm{CH}_{3}$ peaks which are detected without splitting, therefore it is possible that the transfer of magnetization from the protons to carbons within the $\mathrm{CH}_{3}$ groups in amorphous and crystalline regions is essentially the same. An agreement between intensities obtained for $\mathrm{CH}_{3}$ carbons from experiments with $\mathrm{CP}$ (Figure 4) and without $\mathrm{CP}$ (mentioned in further text) supports this assumption.

The $T_{1 \rho}\left({ }^{13} \mathrm{C}\right)$ measurements at elevated temperatures are also relevant in this connection. The $\mathrm{CH}_{2}$, $\mathrm{CH}$ and $\mathrm{CH}_{3}$ resonance lines of the spectra detected after increasing spin-lock pulses were deconvoluted into two lines and the integral intensities versus spin-lock pulse duration were plotted for all peaks. The relaxation curves were fitted by single exponential decays. The $T_{1 \rho}\left({ }^{13} \mathrm{C}\right)$ data are summarised in Table 2. The $T_{1 \rho}\left({ }^{13} \mathrm{C}\right)$ relaxation times associated with the left side peaks of the $\mathrm{CH}_{2}, \mathrm{CH}$ and $\mathrm{CH}_{3}$ carbon types in amorphous regions are at $64^{\circ} \mathrm{C}$ shorter than that associated with the respective right side peaks corresponding to crystalline regions. In the case of the $\mathrm{CH}_{2}$ and $\mathrm{CH}$ groups at $64^{\circ} \mathrm{C}$ the shorter and the longer relaxation times can be assigned to the relaxation processes in the amorphous and the crystalline phase, respectively, and the two types of $\mathrm{CH}_{3}$ carbons relax with different relaxation times reflecting two different molecular processes. For amorphous $\mathrm{CH}_{2}$ and $\mathrm{CH}$ carbons the $T_{1 \rho}\left({ }^{13} \mathrm{C}\right)$ values at $90^{\circ} \mathrm{C}$ are substantially longer than those at $64^{\circ} \mathrm{C}$ resulting in similar relaxation times of both components of $\mathrm{CH}_{2}$ and $\mathrm{CH}$ signals. This result confirms that for the amorphous component we operate in the high-temperature part of the relaxation curve where a higher $T_{1 \rho}\left({ }^{13} \mathrm{C}\right)$ corresponds to higher mobility (shorter correlation time). Subsequently, from comparison of $T_{1 \rho}\left({ }^{13} \mathrm{C}\right)$ values obtained for main chain $\mathrm{CH}_{2}$ and $\mathrm{CH}$ carbons in m-iPP and ZN-iPP (cf. Table 2) it follows that the rate of the segmental motion in mid- $\mathrm{kHz}$ region is in $\mathrm{m}-\mathrm{iPP}$ and $\mathrm{ZN}-\mathrm{iPP}$ virtually the same.

The CP MAS ${ }^{13} \mathrm{C}$ NMR spectra measured for $\mathrm{m}$-iPP and $\mathrm{ZN}$-iPP at different temperatures were deconvoluted in the same manner as mentioned above and the chemical shifts of the separated lines were determined. The temperature dependences of the chemical shifts depicted in Figure 5 show that the chemical shifts of $\mathrm{CH}$ carbons in the crystalline regions of the sample are the same in the whole temperature range investigated, however, the chemical shifts of the $\mathrm{CH}_{2}$ and $\mathrm{CH}_{3}$ lines show slight gradual increase as a function of the temperature within the whole temperature range and within the temperature range above $55^{\circ} \mathrm{C}$, respectively.

Table 2. The rotating frame spin lattice relaxation times $T_{1 \rho}\left({ }^{13} \mathrm{C}\right)$ in $\mathrm{m}-\mathrm{iPP}$ and $\mathrm{ZN}-\mathrm{iPP}$ related to $\mathrm{CH}_{2}, \mathrm{CH}_{\text {and }} \mathrm{CH}_{3}$ carbons in amorphous and crystalline regions. Measurements were carried out at 64 and $90^{\circ} \mathrm{C}$

\begin{tabular}{|c|c|c|c|c|c|c|c|}
\hline \multirow{3}{*}{ Sample } & \multirow{3}{*}{$T\left[{ }^{\circ} \mathrm{C}\right]$} & \multicolumn{6}{|c|}{$T_{1 \rho}\left({ }^{13} \mathrm{C}\right)^{\mathrm{a}}[\mathrm{ms}]$} \\
\hline & & \multicolumn{2}{|c|}{$\mathrm{CH}_{2}$} & \multicolumn{2}{|c|}{$\mathrm{CH}$} & \multicolumn{2}{|c|}{$\mathrm{CH}_{3}$} \\
\hline & & amorphous & crystalline & amorphous & crystalline & amorphous & crystalline \\
\hline \multirow{2}{*}{ m-iPP } & 64 & 3.3 & 26.1 & 6.1 & 26.9 & 20.1 & 40.5 \\
\hline & 90 & 17.0 & 23.0 & 22.2 & 22.6 & 21.1 & 39.8 \\
\hline \multirow{2}{*}{ ZN-iPP } & 64 & 3.6 & 29.8 & 7.0 & 30.2 & 23.6 & 47.6 \\
\hline & 90 & 17.4 & 29.6 & 23.2 & 29.4 & 23.8 & 46.1 \\
\hline
\end{tabular}

acstimated error $\pm 10 \%$. 


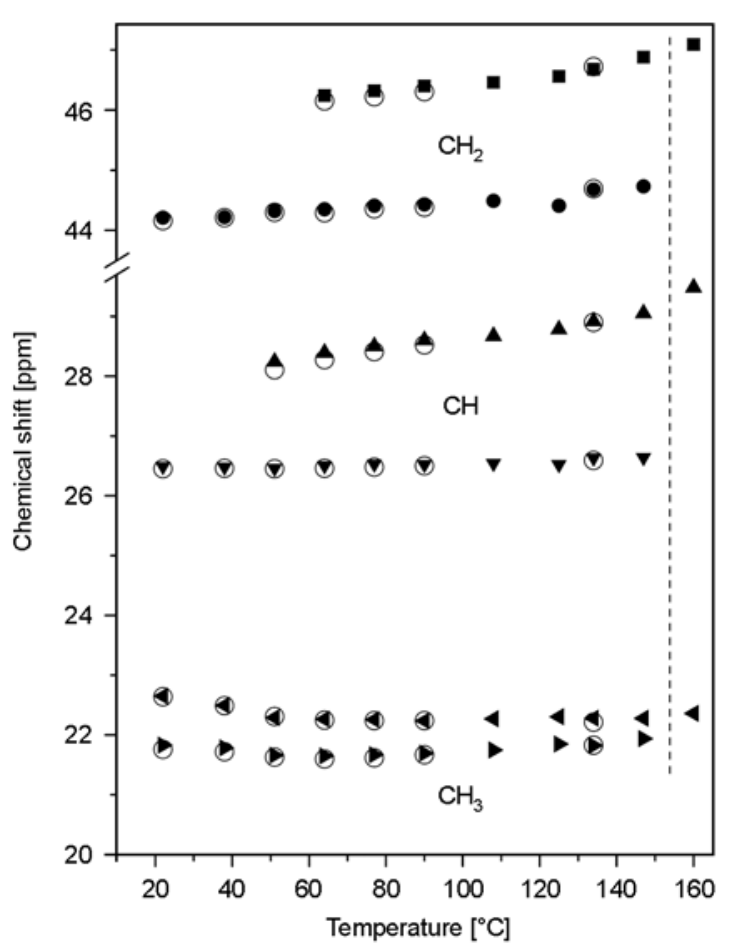

Figure 5. The temperature dependences of the chemical shift of the lines related to the particular carbon types of m-iPP (solid symbols) and ZN-iPP (open circles). For all carbon types larger chemical shifts correspond to amorphous carbons and smaller chemical shifts correspond to crystalline carbons. A vertical dashed line separates the values obtained for solid polymers from those obtained for the molten m-iPP sample

The chemical shifts of the $\mathrm{CH}_{2}$ and $\mathrm{CH}$ lines related to the amorphous regions as a function of temperature show increasing tendency and the chemical shift of the amorphous $\mathrm{CH}_{3}$ groups is constant within the broad temperature range above $55^{\circ} \mathrm{C}$. It is evident, however, that the chemical shifts of all amorphous resonance lines approach very closely the chemical shifts observed for the molten m-iPP at $160^{\circ} \mathrm{C}$.

Based on the results mentioned above it can be concluded that at room temperature, which is slightly above the glass transition temperature, $\mathrm{m}$-iPP and $\mathrm{ZN}$-iPP samples behave in the NMR experiments as if they were in the glassy state with undistinguished motion between the amorphous and crystalline regions. The rise of the temperature results in more conspicuous enhancement of the mobility of the chain segments in the amorphous regions and the quick conformation changes associated with the motion in these regions result in the new resonance lines in close proximity to the lines observed at room temperature. The fact that the chemical shifts of the lines related to the $\mathrm{CH}_{2}$ and $\mathrm{CH}$ groups in amorphous regions gradually increase up to the chemical shift observed for the molten sample indicates that the conformation changes between the glassy and molten state are implemented gradually in the amorphous regions and, on the other hand, the abrupt change of conformations in crystalline domains in the process of melting can be drawn from the data in Figure 5.

The temperature dependence of the chemical shift of the resonance lines related to the $\mathrm{CH}_{3}$ groups in amorphous regions where the values in the solid polymer are indistinguishable from that in molten state indicates that the $\mathrm{CH}_{3}$ groups in amorphous regions can rotate virtually freely within a broad temperature range. In the case of crystalline regions the increase of the temperature causes that $\mathrm{CH}_{3}$ groups rotate gradually in a similar way as in molten sample. All but fluent change of the $\mathrm{CH}_{3}$ group mobility between crystalline and molten state can be deduced from Figure 5 .

The relative integral intensities of the lines related to the particular groups were estimated for both samples from the spectra obtained by deconvolution. Under the applied CP the relative integral intensities of the lines related to the $\mathrm{CH}_{2}$ and $\mathrm{CH}$ groups in amorphous regions and the intensities of the lines related to these groups in crystalline regions are at variance with the values of the degree of crystallinity as obtained by DSC (cf. Figure 1 and Table 1). As mentioned above, a motion restricts the magnetisation transfer from the ${ }^{1} \mathrm{H}$ spin system to that of the ${ }^{13} \mathrm{C}$ in the CP MAS NMR experiment. This is the reason why relative integral intensities of the lines related to crystalline regions are higher in CP MAS NMR spectra than the respective degrees of crystallinity. For the molten sample m-iPP the CP is completely inefficient.

For quantitative evaluations, the MAS DD ${ }^{13} \mathrm{C}$ NMR spectra (without $\mathrm{CP}$ ) were measured at temperature $90^{\circ} \mathrm{C}$ (Figure 6). The evident difference between the spectra measured by the two different techniques at the same temperature can be seen comparing the spectra measured without $\mathrm{CP}$ and with $\mathrm{CP}$ as shown in Figure 6. Besides higher intensities of the lines of the $\mathrm{CH}_{2}$ and $\mathrm{CH}$ carbons in amorphous regions also 

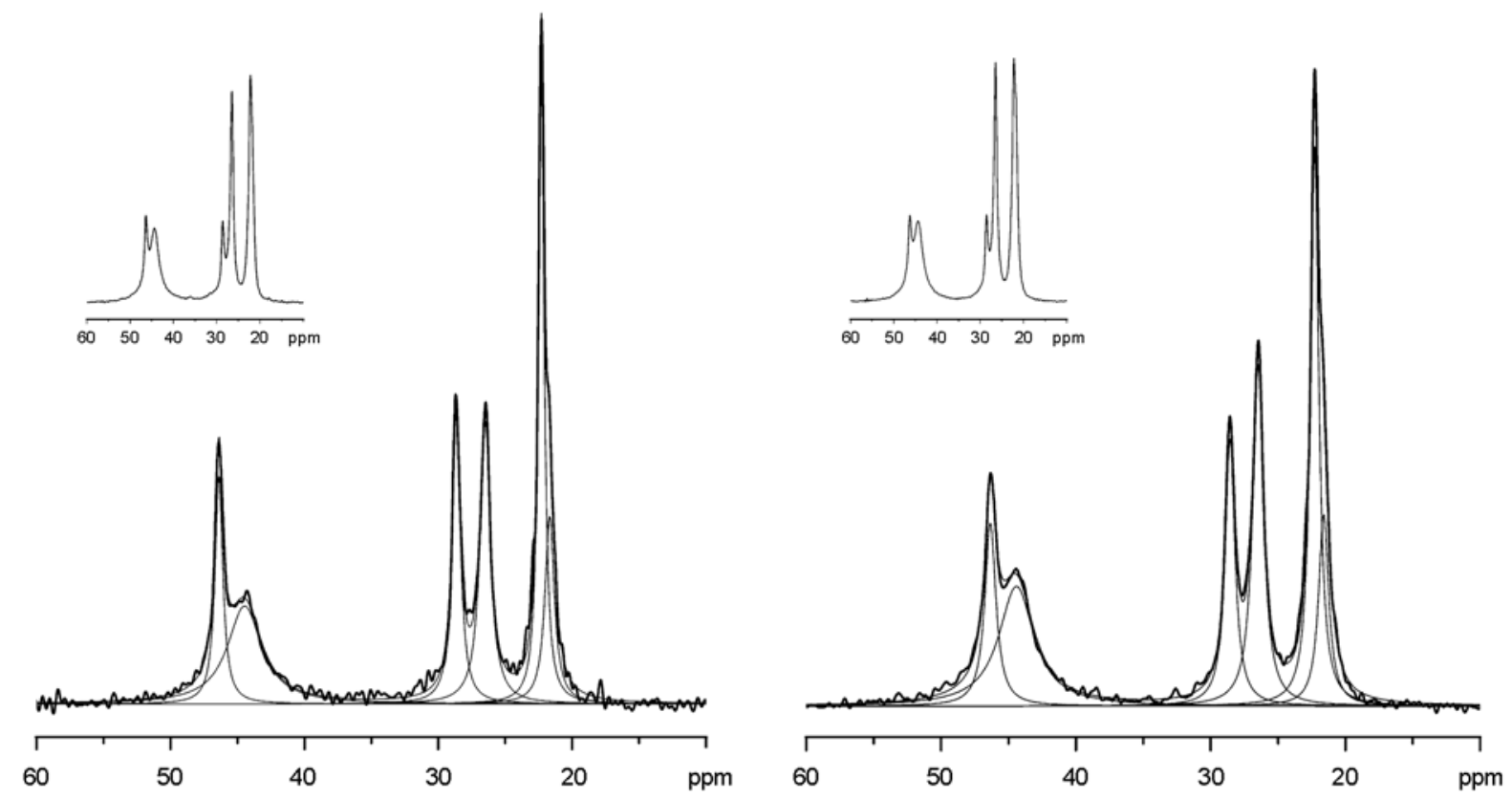

Figure 6. Deconvolutions of the normalized DD MAS (without $\mathrm{CP}$ ) ${ }^{13} \mathrm{C}$ NMR spectra of m-iPP (left) and ZN-iPP (right) measured at $90^{\circ} \mathrm{C}$. Corresponding DD CP MAS ${ }^{13} \mathrm{C}$ NMR spectra measured at the same temperature are shown in the insets for comparison

better resolved two signal components of the $\mathrm{CH}_{3}$ carbons are observed in MAS DD ${ }^{13} \mathrm{C}$ NMR spectra without $\mathrm{CP}$.

Deconvolution of the spectra measured for the miPP and $\mathrm{ZN}-\mathrm{iPP}$ is also shown in Figure 6 and the relative integral intensities of the individual lines determined by this procedure are summarized for both studied samples in Table 3. In spite of the fact that we have used a two-phase model of polymer with crystalline and amorphous regions only, while three-phase model takes into account also interphase regions of the partially crystalline polymer $[7,11,17]$, the relative integral intensities of the lines related to the main chain $\mathrm{CH}_{2}$ and $\mathrm{CH}$ groups in the crystalline regions of both samples are in accordance with the degree of the crystallinity obtained by DSC (cf. Table 1). No changes of the degree of the crystallinity with time were observed in the NMR spectra.

Table 3. The relative integral intensities of the lines of $\mathrm{CH}_{2}$ and $\mathrm{CH}$ carbons as obtained by deconvolution of the MAS DD ${ }^{13} \mathrm{C}$ NMR spectra measured for $\mathrm{m}$ iPP and $\mathrm{ZN}-\mathrm{iPP}$ at $90^{\circ} \mathrm{C}$

\begin{tabular}{|l|c|c|c|c|}
\hline \multirow{3}{*}{ Sample } & \multicolumn{4}{|c|}{ Integral intensity } \\
\cline { 2 - 5 } & \multicolumn{2}{|c|}{$\mathbf{C H}_{\mathbf{2}}$} & \multicolumn{2}{c|}{ CH } \\
\cline { 2 - 5 } & amorphous & crystalline & amorphous & crystalline \\
\hline m-iPP & 0.44 & 0.56 & 0.46 & 0.54 \\
\hline ZN-iPP & 0.41 & 0.59 & 0.41 & 0.59 \\
\hline
\end{tabular}

The line widths should be also briefly mentioned. The fact that the resonance lines related to the amorphous regions at $90^{\circ} \mathrm{C}$ are narrower than the corresponding lines related to the crystalline regions (cf. Figure 6) was expected and it applies to both $\mathrm{CH}_{2}$ and $\mathrm{CH}$ groups and both samples. The higher mobility of the amorphous chain segments in comparison with the helix chains in the crystalline domains accounts for the differences of the line widths. Somewhat larger spatial restraints of the chain motion in $\mathrm{ZN}-\mathrm{iPP}$ can be deduced from the broader amorphous $\mathrm{CH}_{2}$ and $\mathrm{CH}$ lines for $\mathrm{ZN}-\mathrm{iPP}$ in comparison with m-iPP (by 22 and $7 \mathrm{~Hz}$ for $\mathrm{CH}_{2}$ and $\mathrm{CH}$ carbons, respectively).

\section{Conclusions}

High resolution ${ }^{13} \mathrm{C}$ NMR spectra were obtained for $\mathrm{m}$-iPP and $\mathrm{ZN}-\mathrm{iPP}$ samples using $\mathrm{CP}$ and MAS techniques. The CP MAS NMR spectra were recorded in the temperature range from room temperature up to $160^{\circ} \mathrm{C}$. Three resonance lines corresponding to $\mathrm{CH}_{2}, \mathrm{CH}$ a $\mathrm{CH}_{3}$ groups were observed in the spectra measured at room temperature which is approximately $10 \mathrm{~K}$ above the glass transition temperature of studied samples and also at $160^{\circ} \mathrm{C}$ for molten sample. The relatively large widths of resonance lines detected at room temperature reflect low mobility of iPP chains and wide distribution of chains con- 
formations. On contrary very narrow resonance lines detected in molten sample reflect fast conformational changes. In the spectra measured above $50^{\circ} \mathrm{C}$ the resonance lines corresponding to $\mathrm{CH}_{2}$ and $\mathrm{CH}$ carbons were split into two components and assigned to chains in amorphous and crystalline regions of iPP. Temperature dependences of chemical shifts of split lines show that the conformation changes between the glassy and molten state are implemented gradually with increasing temperature while in crystalline regions the conformational changes are observed only under melting process. The existence of two components was revealed also for $\mathrm{CH}_{3}$ carbons. The crystallinity of the studied samples was determined from the deconvoluted MAS ${ }^{13} \mathrm{C}$ NMR spectra measured without $\mathrm{CP}$ at $90^{\circ} \mathrm{C}$. Deconvolutions of $\mathrm{CH}_{2}$ and $\mathrm{CH}$ lines give essentially the same crystallinities; the obtained values agree well with those determined using DSC. While virtually the same rate of the segmental motion in mid- $\mathrm{kHz}$ region in amorphous $\mathrm{m}-\mathrm{iPP}$ and $\mathrm{ZN}-\mathrm{iPP}$ chains follows from $T_{1 \rho}\left({ }^{13} \mathrm{C}\right)$ values, larger $\mathrm{CH}_{2}$ and $\mathrm{CH}$ linewidths in ${ }^{13} \mathrm{C}$ and ${ }^{1} \mathrm{H}$ NMR spectra indicate somewhat larger restraints of the motion in $\mathrm{ZN}-\mathrm{iPP}$ in comparison with m-iPP.

\section{Acknowledgements}

We support research activities in Slovakia/Project is cofinanced from EU funds. This paper was developed within the Project 'Centre of Excellence of the Integrated Research \& Exploitation of the Advanced Materials and Technologies in the Automotive Electronics', ITMS 26220120055.

One of the authors (IC) appreciates the financial support of this research through Slovak Research and Development Agency (grant APVV-0226-06).

\section{References}

[1] Kaempfer D., Thomann R., Mülhaupt R.: Melt compounding of syndiotactic polypropylene nanocomposites containing organophilic layered silicates and in situ formed core/shell nanoparticles. Polymer, 43, 29092916 (2002).

DOI: 10.1016/S0032-3861(02)00113-1

[2] Bond E. B., Spruiell J. E.: The effects of atacticity, comonomer content, and configurational defects on the equilibrium melting temperature of monoclinic isotactic polypropylene. Journal of Applied Polymer Science, 81, 229-236 (2001).

DOI: $\underline{10.1002 / a p p .1433}$
[3] Bunn A., Cudby M. E. A., Harris R. K., Packer K. J., Say B. J.: Solid-state high-resolution ${ }^{13} \mathrm{C}$ n.m.r. spectra of polypropene. Journal of the Chemical Society, Chemical Communications, 15-16 (1981).

DOI: $10.1039 / \mathrm{C} 39810000015$

[4] Bunn A., Cudby M. E. A., Harris R. K., Packer K. J., Say B. J.: High resolution ${ }^{13} \mathrm{C}$ n.m.r. spectra of solid isotactic polypropylene. Polymer, 23, 694-698 (1982). DOI: 10.1016/0032-3861(82)90053-2

[5] Lyerla J. R., Yannoni C. S.: High-resolution carbon13 NMR of polymers in the solid state. IBM Journal of Research and Development, 27, 302-312 (1983). DOI: $10.1147 /$ rd.274.0302

[6] Gomez M. A., Tanaka H., Tonelli A. E.: High-resolution solid-state ${ }^{13} \mathrm{C}$ nuclear magnetic resonance study of isotactic polypropylene polymorphs. Polymer, 28, 2227-2232 (1987). DOI: $10.1016 / 0032-3861(87) 90378-8$

[7] Saito S., Moteki Y., Nakagawa M., Horii F., Kitamura R.: High-resolution solid-state ${ }^{13} \mathrm{C}$ NMR study of isotactic polypropylenes isothermally crystallized from the melt. Macromolecules, 23, 3256-3260 (1990). DOI: $10.1021 / \mathrm{ma} 00215 \mathrm{a} 010$

[8] Tanaka H.: ${ }^{13} \mathrm{C}$ magnetic relaxation times in isotactic polypropylene. European Polymer Journal, 27, 565572 (1991).

DOI: $10.1016 / 0014-3057(91) 90137-D$

[9] Zeigler R. C.: Dynamics of polypropene and propeneethylene copolymers at temperatures above ambient. Macromolecular Symposia, 86, 213-227 (1994). DOI: $10.1002 /$ masy. 19940860117

[10] Tonelli A. E.: High resolution NMR as a local probe of structure, conformation, and mobility in solid polymers. Journal of Molecular Structure, 355, 105-119 (1995).

DOI: 10.1016/0022-2860(95)08901-7

[11] Kitamaru R.: Phase structure of polyethylene and other crystalline polymers by solid-state ${ }^{13} \mathrm{C}$ NMR. Advances in Polymer Science, 137, 41-102 (1998). DOI: $10.1007 / 3-540-69685-72$

[12] Alamo R. G., Blanco J. A., Carrilero I., Fu R.: Measurement of the ${ }^{13} \mathrm{C}$ spin-lattice relaxation time of the non-crystalline regions of semicrystalline polymers by a cp MAS-based method. Polymer, 43, 1857-1865 (2002). DOI: 10.1016/S0032-3861(01)00761-3

[13] Miyoshi T., Mamun A., Hu W.: Molecular ordering and molecular dynamics in isotactic-polypropylene characterized by solid state NMR. The Journal of Physical Chemistry B, 114, 92-100 (2010). DOI: $10.1021 / j p 908649 y$ 
[14] Hu W-G., Schmidt-Rohr K.: Polymer ultradrawability: The crucial role of $\alpha$-relaxation chain mobility in the crystallites. Acta Polymerica, 50, 271-285 (1999).

DOI: $10.1002 /($ SICI) 1521-4044(19990801)50:8<271::

$$
\text { AID-APOL271>3.0.CO;2-Y }
$$

[15] Zhang X., Zhao Y., Wang Z., Zheng C., Dong X., Su Z., Sun P., Wang D., Han C. C., Xu D.: Morphology and mechanical behavior of isotactic polypropylene (iPP)/syndiotactic polypropylene (sPP) blends and fibers. Polymer, 46, 5956-5965 (2005).

DOI: $10.1016 /$ j.polymer.2005.05.004
[16] Bielecki A., Burum D. P.: Temperature dependence of ${ }^{207} \mathrm{~Pb}$ MAS spectra of solid lead nitrate. An accurate, sensitive thermometer for variable-temperature MAS. Journal of Magnetic Resonance, Series A, 116, 215-220 (1995).

DOI: $10.1006 /$ jmra.1995.0010

[17] Ševčovič L., Mucha L'.: Study of stretched polypropylene fibres by ${ }^{1} \mathrm{H}$ pulsed and CW NMR spectroscopy. Solid State Nuclear Magnetic Resonance, 36, 151-157 (2009).

DOI: $10.1016 /$ j.ssnmr.2009.09.001 